\title{
ĐẶC ĐIỂM CẤU TRÚC ĐỘ DẪN ĐIỆN VÀ MỐI QUAN HỆ VỚI DI THƯỜNG ĐỊA NHIÊTT Ở ĐỚI ĐỨT GÃY SÔNG HỒNG
}

\author{
ĐOÀN VĂN TUYẾN, ĐINH VĂN TOÀN \\ E-mail: doanvantuyen@yahoo.com \\ Viện Địa chất - Viện Khoa học và Công nghệ Việt Nam \\ Ngày nhận bài: 31-3-2011
}

\section{Mở đầu}

Trên lãnh thổ Việt Nam, đới đứt gãy Sông Hồng (ĐGSH) kéo dài từ Lào Cai tới vịnh Bắc Bộ. Ở khu vực thuộc các tỉnh Lào Cai, Yên Bái, Phú Thọ, nơi có địa hình núi cao còn lộ các đá có tuổi địa chất từ cổ (dải núi Con Voi) đến trẻ cho phép các nhà địa chất có điều kiện khảo sát và tiến hành nhiều công cụ phân tích để đánh giá cơ chế và quá trình phát triển của đới đứt gãy này. Ở khu vực từ Việt Trì ra bờ biển, nơi có địa hình đồi thấp và đồng bằng, ĐGSH chìm sâu dưới các trầm tích $\mathrm{MZ}$ - KZ và chỉ nhận biết được thông qua tài liệu địa vật lý. Các dải gradient cao trên bản đồ dị thường trọng lực cho phép nhận biết sự phân bố các đứt gãy chính trong ĐGSH gồm đứt gãy Sông Hồng, Sông Chảy, Sông Lô và một số đứt gãy bậc cao hơn phát triển mạnh có xu hướng mở rộng ra phía biển. Tài liệu địa chấn thăm dò dầu khí ở trũng Sông Hồng và trên vịnh Bắc Bộ thể hiện rõ nét sự biến động mạnh mẽ các lớp trầm tích KZ [14]. Ở phần đông nam vùng trũng đã xác định được một dị thường dòng nhiệt $100 \mathrm{~mW} / \mathrm{m}^{2}$, cao hơn nhiều so với dòng nhiệt bình thường $\left(60-65 \mathrm{~mW} / \mathrm{m}^{2}\right)$, trong lỗ khoan thăm dò dầu khí ở độ sâu $3.000 \mathrm{~m}$ đã đo được nhiệt độ $>140^{\circ} \mathrm{C}$. Ngoài ra, trên diện rộng của trũng Sông Hồng có nhiều điểm xuất lộ nước nóng tự nhiên có nhiệt độ cao $>40^{\circ} \mathrm{C}[1,3]$. Điều đó chứng tỏ ĐGSH ở khu vực này có mức độ và cơ chế hoạt động mạnh mẽ đặc biệt, không chỉ liên quan đến các vận động dịch trượt mà có thể còn chịu tác động của các hoạt động địa động lực từ bên dưới vỏ Trái Đất, nhưng còn ít được nghiên cứu $[1,13]$.
Trong các thông tin địa vật lý, tính chất dẫn điện trong phương pháp đo sâu từ tellua có ưu thế nổi trội, nó không chỉ phản ánh trạng thái cấu trúc (trạng thái tĩnh) của đất đá ở độ sâu lớn, mà còn có mối quan hệ chặt chẽ với các yếu tố khoáng hóa và nhiệt độ trong nước địa nhiệt cũng như nguồn địa nhiệt, một trong những chỉ thị về các hoạt động sâu từ lòng đất. Trên một tuyến đo sâu từ tellua cắt qua ĐGSH từ thị trấn Lương Sơn (tỉnh Hòa Bình) qua Hà Nội đến thành phố Bắc Ninh do Viện Địa chất (Viện Khoa học và Công nghệ Việt Nam) và Viện Vật lý Địa cầu Paris (Pháp) thực hiện năm 1996 đã nhận được mặt cắt cấu trúc điện trở suất của vỏ Trái Đất và phần trên manti. Phân tích mối quan hệ giữa tính chất dẫn điện và các biểu hiện địa nhiệt trong vùng có khả năng cung cấp thêm những cứ liệu để luận giải điều kiện địa động lực của ĐGSH ở khu vực này.

\section{2. Đặc điểm trường địa nhiệt ở vùng trũng Sông Hồng}

Vùng trũng Sông Hồng chưa được nghiên cứu đầy đủ nhưng là nơi có tài liệu địa nhiệt phong phú nhất trên lãnh thổ Việt Nam (hình 1). Từ các tài liệu đo nhiệt độ trong các lỗ khoan dầu khí (đến độ sâu $3.000 \mathrm{~m}$ ) ở phần đông nam vùng trũng, các lỗ khoan địa chất thủy văn (đến độ sâu $200 \mathrm{~m}$ ) và đo độ dẫn nhiệt mẫu đá đã xác định được hơn 40 giá trị dòng nhiệt $[1,3]$. Vùng dị thường dòng nhiệt cao nhất $\left(100 \mathrm{~mW} / \mathrm{m}^{2}\right)$ ghi nhận được ở vùng Kiến Xương - Tiền Hải (tỉnh Thái Bình). Nhiệt độ ở đáy lỗ khoan sâu nhất $(3.000 \mathrm{~m})$ đạt $>140^{\circ} \mathrm{C}$. Vùng dị thường tương đối cao $\left(>70 \mathrm{~mW} / \mathrm{m}^{2}\right)$ có khả năng phân bố trên một diện tích lớn gồm các tỉnh Thái 
Bình, Nam Định, Hưng Yên, Hà Nam và có xu thế phát triển ra phía biển thuộc vịnh Bắc Bộ. Trên bình đồ, vùng dị thường địa nhiệt này phân bố trong phạm vi giữa các đứt gãy Vĩnh Ninh ở phía đông bắc và đứt gãy Sông Hồng ở phía tây nam và có $\mathrm{xu}$ thế phát triển kéo dài về phía tây bắc theo hướng các đứt gãy Sông Hồng và Sông Chảy $[3,13]$.

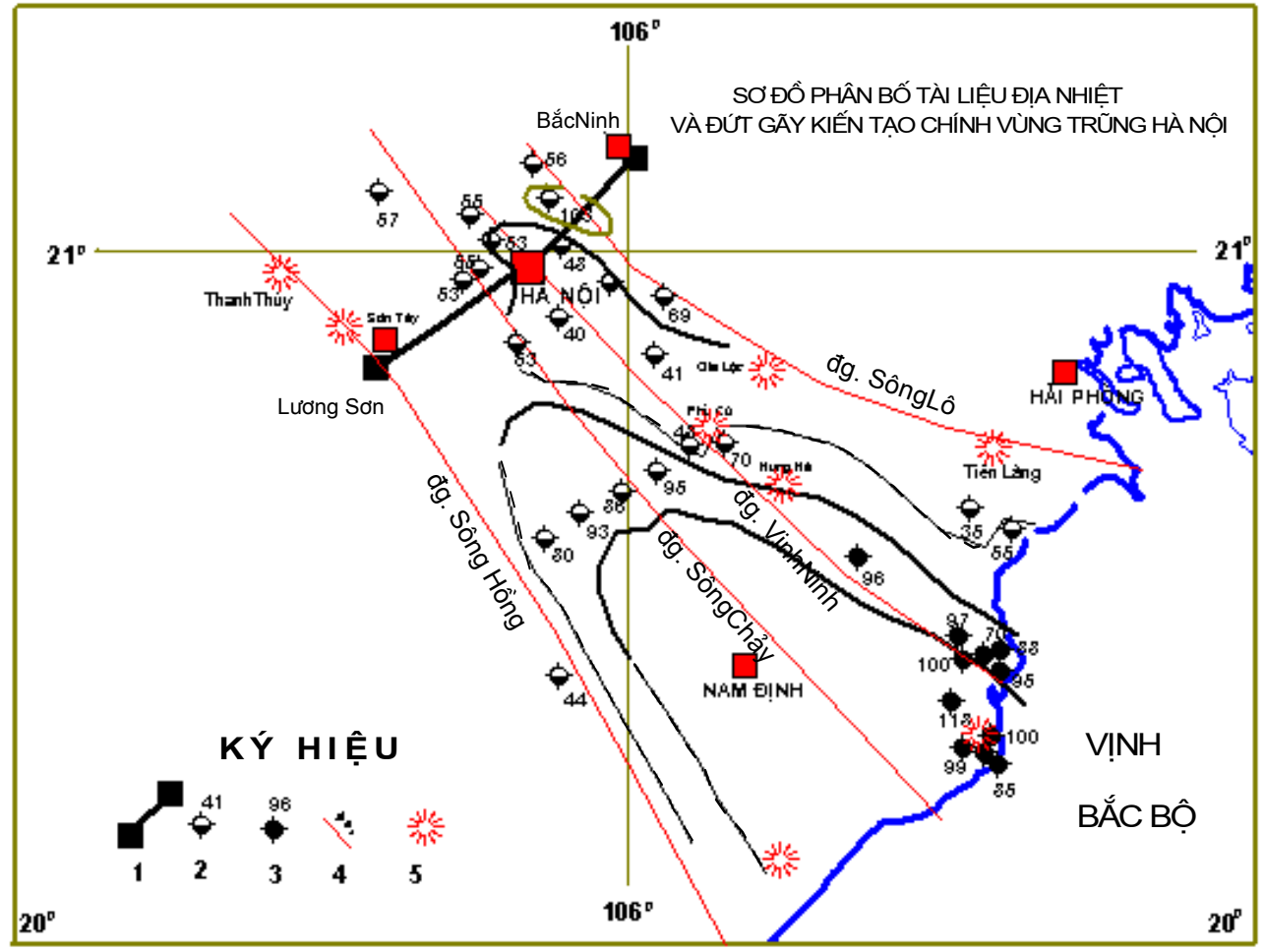

Hình 1. Phân bố dị thường địa nhiệt và đứt gãy kiến tạo chính ở vùng trũng Sông Hồng Chú giải: 1- Tuyến đo sâu từ tellua Lương Sơn - Bắc Ninh; Giá trị dòng nhiệt $\left(\mathrm{mW} / \mathrm{m}^{2}\right)$ : 2- Từ lỗ khoan địa chất thủy văn; 3- Từ lỗ khoan dầu khí; 4- Đứt gãy kiến tạo; 5- Nguồn nước nóng $>40^{\circ} \mathrm{C}$

Ngoài ra, tại khu vực huyện Đông Anh (Hà Nội), gần nơi giao cắt tuyến đo từ tellua Lương Sơn - Bắc Ninh với đứt gãy Sông Lô cũng ghi nhận được giá trị dòng nhiệt cao cục bộ (gần $100 \mathrm{~mW} / \mathrm{m}^{2}$ ). Phần diện tích còn lại có dòng nhiệt chủ yếu trong khoảng $50-60 \mathrm{~mW} / \mathrm{m}^{2}$ là giá trị bình thường trung bình của vỏ Trái Đất.

Trong phạm vi rộng của trũng Sông Hồng đã phát hiện trong lỗ khoan hay xuất lộ hàng loạt điểm nước khoáng nóng có nhiệt độ $>40^{\circ} \mathrm{C}$ (Gia Lộc - Hải Dương, Tiên Lãng - Hải Phòng, Phù Cù̀ - Hưng Yên, Hưng Hà, Tiền Hải - Thái Bình, Ba Vì - Hà Nội, Thanh Thủy - Phú Thọ, Kim Sơn Ninh Bình).

Sự xuất hiện dị thường dòng nhiệt cao và phân bố rộng rãi nguồn nước khoáng nóng ở vùng trũng Sông Hồng là một trong những chỉ thị địa chất kiến tạo chứng tỏ ĐGSH ở khu vực này hoạt động mạnh mẽ liên quan đến các quá trình vận động địa động lực sâu dưới vỏ Trái Đất $[5,7]$.

\section{3. Đặc điểm phân bố độ dẫn điện trong vỏ Trái Đất trên tuyến đo sâu từ tellua Lương Sơn - Bắc Ninh}

\subsection{So lược về thu thập, xử lý và phân tích tài liệu tù̀ tellua}

Thu thập số liệu trên thực địa tại mỗi điểm đo bằng một hệ thiết bị ghi các dao động trường điện từ tự nhiên theo hai phương vuông góc trên mặt đất gồm thành phần điện $\mathrm{E}_{\mathrm{xy}}, \mathrm{E}_{\mathrm{yx}}$ và thành phần từ $\mathrm{H}_{\mathrm{xy}}$, $\mathrm{H}_{\mathrm{yx}}$, trong đó $\mathrm{x}$ là ký hiệu quy ước trục có hướng vuông góc với phương kéo dài cấu trúc (ở đây là phương tuyến đo), còn y là trục theo phương kéo dài cấu trúc. Các tín hiệu dao động trên được xử lý thông tin bằng các phần mềm chuyên dụng để nhận được một loạt các tham số đo sâu từ tellua là 
những cặp đôi biểu thức mô tả sự quan hệ phụ thuộc hay biến đổi tính chất môi trường vào chu kỳ dao động hay tần số của trường điện từ: Điện trở suất và pha Cagniard - Tikhonov (mô hình 1D), điện trở suất và pha tensơ, Skew, tham số $\theta, \ldots$. (tính chất $2 \mathrm{D}$ và $3 \mathrm{D}$ ), trong đó tham số điện trở suất biểu kiến là quan trọng được sử dụng phổ biến nhất. Ví dụ trường hợp đơn giản là biểu thức điện trở suất do các nhà khoa học Cagniard (Pháp) và Tikhonov (Nga) đề xuất: $\rho_{T}=\frac{T}{2 \pi \mu_{0}}\left|Z_{n}\right|^{2}$, dạng biểu đồ của biểu thức này được gọi là đường cong đo sâu từ tellua; trong đó:

$T$ - là đặc trưng chu kỳ dao động của thành phần điện từ; $\mu_{0}$ - là hằng số từ thẩm trong không khí; $Z_{n}$ - giá trị tổng trở biểu kiến là biểu thức phức tạp chứa các tham số đặc trưng trường điện từ và môi trường có $n$ lớp, ví dụ với số lớp $n=3$ :

$$
\begin{aligned}
& Z_{3}=\frac{E x y}{H y x}=-\frac{E y x}{H x y}=-\frac{i \omega}{k_{1}} c t h \\
& \left\{k_{1} h_{1}+\operatorname{arcth}\left[\sqrt{\rho_{2} / \rho_{1}} \operatorname{cth}\left(k_{2} h_{2}+\operatorname{arcth} \sqrt{\rho_{3} / \rho_{2}}\right)\right]\right\}
\end{aligned}
$$

Trong đó: $\omega$ - là pha dao động của trường điện từ; $\mathrm{k}_{\mathrm{m}}, \rho_{\mathrm{m}}, \mathrm{h}_{\mathrm{m}}$ - tương ứng hằng số sóng, điện trở suất, chiều dày lớp thứ $\mathrm{m}=1$ đến $\mathrm{n}$ trong môi trường $[11,16]$.

Biểu thức đơn giản điện trở suất $\rho_{\mathrm{T}}$ phụ thuộc tỷ lệ thuận đồng thời với chu kỳ dao động $\mathrm{T}$ và điện trở suất các lớp trong môi trường. Như vậy, để khảo sát độ sâu càng lớn thì phải ghi các dao động điện từ có chu kỳ thời gian càng dài, trong điều kiện cùng một chu kỳ ghi tín hiệu thì môi trường có điện trở suất cao hơn sẽ có độ sâu khảo sát lớn hơn.

Các biểu thức khác của phương pháp đo sâu từ tellua có thể tham khảo trong $[9,11,16]$.

Phân tích tài liệu từ tellua: Các tham số đo sâu từ tellua nhận được từ số liệu đo và kết quả xử lý nêu trên mới chỉ mô tả định tính về môi trường dưới tuyến khảo sát. Để nhận được các tham số (độ sâu phân bố, chiều dày, điện trở suất đặc trưng của các cấu trúc) trong môi trường cần phải thực hiện bước phân tích định lượng hay còn gọi là giải bài toán ngược tài liệu từ tellua. Nội dung công việc này cũng như giải bài toán ngược địa vật lý nói chung thuộc loại bài toán thiết lập không đúng đắn, nên lời giải đa trị và không ổn định, nên để có kết quả phân tích tài liệu từ tellua có thông tin tin cậy và phù hợp thực tế cần có phần mềm đủ mạnh cho khả năng mô phỏng mô hình phức tạp cần thiết, khả năng hội thoại thuận tiện để lựa chọn và đưa vào thông tin thích hợp. Do đó, kỹ năng của người phân tích tài liệu có vai trò hết sức quan trọng $[9$, $11,15]$.

\subsection{Kết quả đo sâu tù̀ tellua trên tuyến Luơng Sơn - Bắc Ninh}

Tài liệu đo sâu từ tellua trên tuyến này nhận được từ kết quả thực hiện trong năm 1996 thông qua một hợp tác giữa Viện Địa chất - Viện Khoa học và Công nghệ Việt Nam và Viện Vật lý Địa cầu Paris (Pháp) [12]. Vị trí tuyến đo được bố trí có phương cắt vuông góc với hướng kéo dài các cấu trúc và đứt gãy của ĐGSH (hình 1). Ngoài tuyến này Viện Địa chất và Viện Vật lý Địa cầu (Viện Khoa học và Công nghệ Việt Nam) còn thực hiện các tuyến cắt qua ĐGSH: Thanh Sơn (Phú Thọ) - Thái Nguyên, Yên Bái - Tuyên Quang, Nam Định - Hải Phòng, tài liệu, kết quả đã được công bố $[10,12]$.

Máy đo trên thực địa là thiết bị LAGAS do Viện Vật lý Địa cầu Paris chế tạo có khả năng thu tín hiệu dao động điện từ trong dải tần số $10^{-3}-10^{3}$ Hz. Trong điều kiện thuận lợi có thể thực hiện ghi số liệu liên tục tại một điểm đo trong thời gian 4 giờ. Xử lý tín hiệu để nhận và kiểm tra chất lượng các tham số đo sâu điện từ như đã giới thiệu ở mục trên với 30 giá trị phân bố trong khoảng chu kỳ $\mathrm{T}=10^{-3}-750$ giây được tiến hành tại thực địa ngay sau khi kết thúc mỗi điểm đo.

Trên tuyến đo Lương Sơn - Bắc Ninh có chiều dài khoảng $75 \mathrm{~km}$ đã nhận được 8 điểm đo có đủ chất lượng để làm tài liệu phân tích có ký hiệu và vị trí: (1) LUS (gần thị trấn Lương Sơn - tỉnh Hòa Bình); (2) STA (gần thị xã Sơn Tây); (3) PTH (gần thị trấn Phúc Thọ); (4) DPH (gần thị trấn Đan Phượng); (5) HN3 (bờ Sông Hồng phía tây Hà Nội); (6) DA2 (gần thị trấn Đông Anh), (7) NDE (xã Nội Duệ - Từ Sơn), (8) LAS (xã Lam Sơn, ngoại vi phía đông thị xã Bắc Ninh. Khoảng cách giữa các điểm đo trong khoảng $5-12 \mathrm{~km}$. Còn một số điểm đo khác chất lượng kém do nhiễu (từ lưới điện, đài phát thanh, vô tuyến truyền hình,...) không được sử dụng, đó là lý do làm cho khoảng cách giữa các điểm đo có chiều dài lớn (hình 2). 


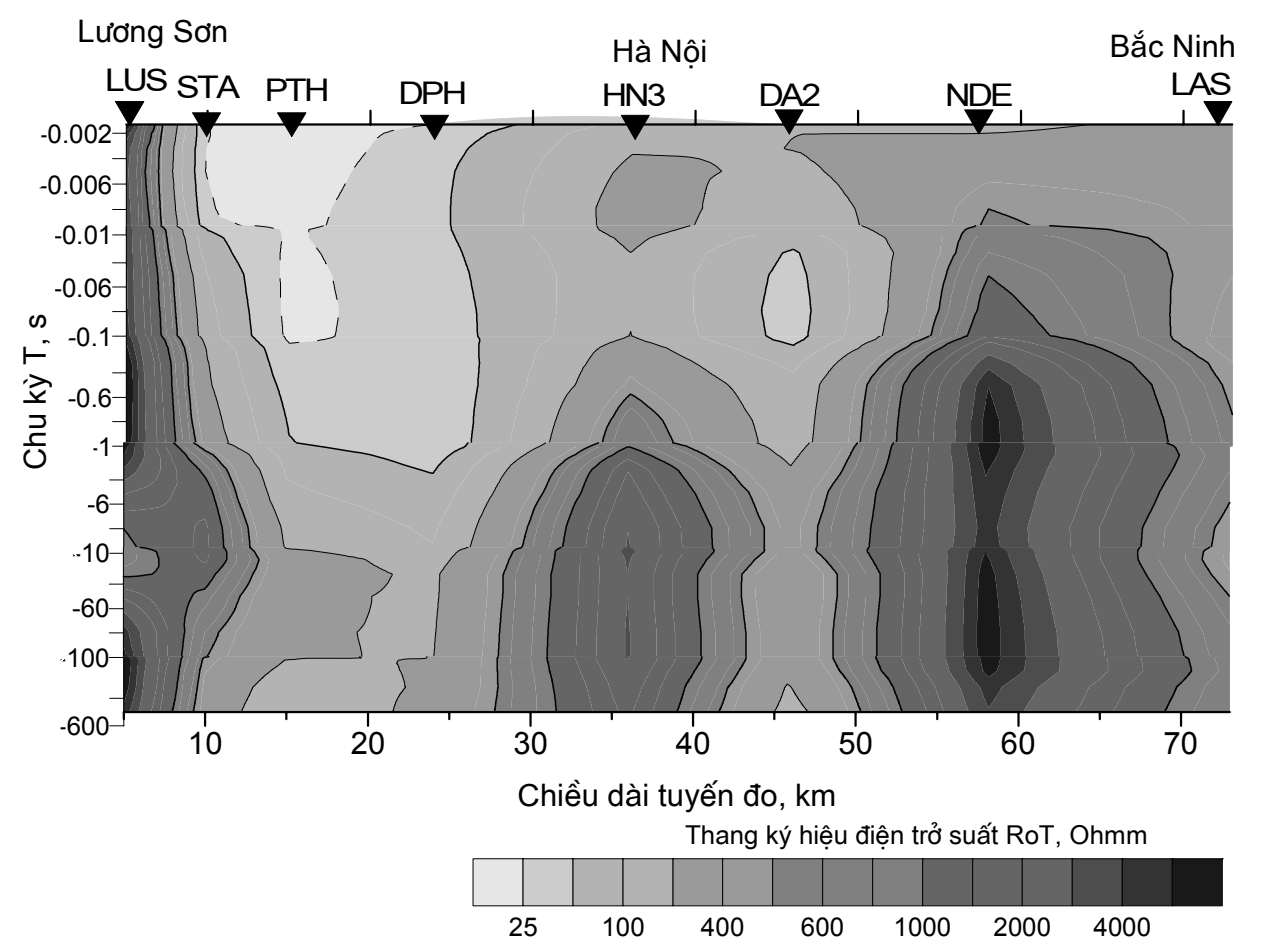

Hình 2. Mặt cắt điện trở suất theo kết quả đo sâu từ tellua tuyến Lương Sơn - Bắc Ninh Chú giải: $\stackrel{\nabla}{\nabla}$ Vị trí và ký hiệu điểm đo từ tellua

Tài liệu đặc trưng kết quả đo từ tellua trên tuyến này là mặt cắt điện trở suất biểu kiến theo hướng tuyến đo thể hiện trên hình 2. Mặt cắt điện trở suất biểu kiến này thể hiện rõ nhất các thông tin khái quát về cấu trúc khu vực khảo sát trên bình đồ kiến tạo, đó là: (1) Cấu trúc điện trở suất thấp $(<300 \Omega \mathrm{m})$ thường trùng với vị trí có đứt gãy chính trên sơ đồ kiến tạo: Cấu trúc có diện phân bố rộng gồm các điểm đo STA, PTH, DPH tương ứng phạm vi giữa hai đứt gãy Sông Hồng và Sông Chảy; cấu trúc diện hẹp tại vị trí điểm đo DA2 tương ứng vị trí đứt gãy Sông Lô; tại điểm đo LAS - cuối tuyến đo, gần với đứt gãy Phả Lại - Đông Triều hay đường 18 (rìa đông bắc); (2) Cấu trúc điện trở suất cao $(>400-5.000 \Omega \mathrm{m})$ phân bố ở phần đầu tuyến (rìa tây nam đứt gãy Sông Hồng), giữa các đứt gãy Sông Chảy và Sông Lô và rìa đông bắc đứt gãy Sông Lô, tức là phân bố xen giữa các cấu trúc điện trở suất thấp nói trên.

Mặt cắt điện trở suất biểu kiến theo phương vuông góc tuyến đo có dạng tương tự và các tham số đo từ tellua khác không có điều kiện trình bày ở đây.

\section{3. Đặc điểm phân bố độ dẫn điện trong vỏ Trái Đất theo kết quả phân tích tài liệu tù tellua}

Ngoài đặc trưng ranh giới phân bố các cấu trúc trên mặt cắt điện trở suất biểu kiến kể trên, tại các điểm đo thể hiện rõ giá trị điện trở suất cực đại $\rho_{\max }$ ứng với chu kỳ $T_{\max }$ mà từ đó giá trị điện trở suất có xu thế phân bố vào đường tiệm cận " $h$ " hợp với trục $T$ góc $-63^{\circ}$, có thể đánh giá được độ sâu phân bố lớp dẫn điện dưới vỏ Trái Đất $[11,16]$ :

$$
h_{M}=0,52 \sqrt{\rho_{\max } \cdot T_{\max }},
$$

Tại các điểm STA, PTH, DPH (hình 2) xác định được: $\rho_{\max } \approx 400 \Omega \mathrm{m}, \quad T_{\max } \approx 60$ giây, $h_{M} \approx 0,52 \times 20 \times 7,74 \cong 80,5 \mathrm{~km}$. Đây chính là tham số độ sâu lớn nhất nhận được theo tài liệu đo.

Theo các tài liệu trọng lực, địa chấn và các tài liệu đã công bố khác, bề mặt Moho ở khu vực nghiên cứu có độ sâu khoảng $30 \mathrm{~km}$.

Dựa vào các thông tin tiên nghiệm nêu trên đã xây dựng mô hình ban đầu, sử dụng phần mềm 
Ip2win-MT theo thuật toán lặp - lựa chọn [4] tính cho cặp số liệu điện trở suất và pha trên toàn tuyến đo đã nhận được kết quả phân tích là mặt cắt cấu trúc điện trở suất thể hiện trên hình 3 sau 8 lần lặp với sai số trung bình (độ lệch giữa kết quả tính mô hình và số liệu đo) $|\delta|<10 \%$.

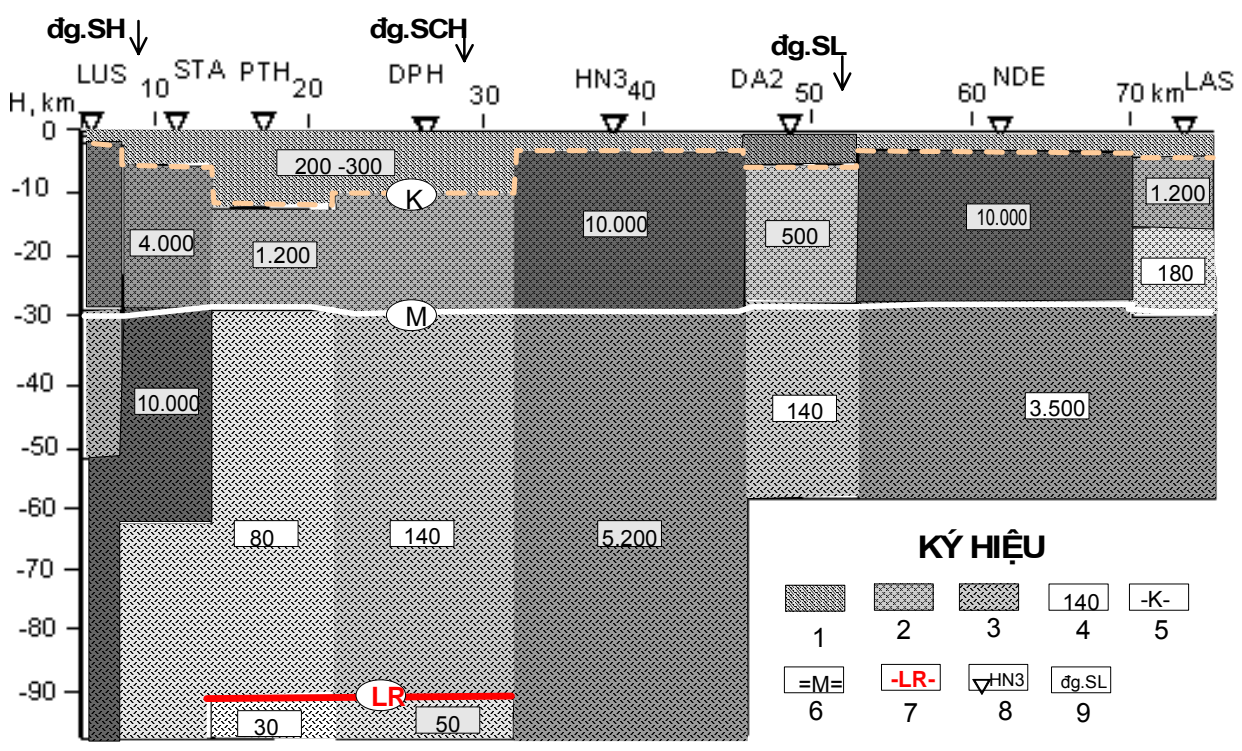

Hình 3. Mặt cắt phân bố cấu trúc điện trở suất theo kết quả phân tích tài liệu từ tellua Tuyến Lương Sơn - Bắc Ninh

Chú giải: 1- Lớp phủ; 2- Vỏ Trái Đất; 3- Manti trên; 4- Giá trị điện trở suất đặc trưng $(\Omega \mathrm{m})$; 5- Bề mặt móng kêt tinh; 6- Bề mặt Moho; 7- Bề mặt khối điện trở suất thấp ở manti trên; 8- Vị trí và ký hiệu điểm đo từ tellua; 9- Vị trí đứt gãy trên bình đồ kiến tạo

Theo chiều sâu mặt cắt thể hiện ba ranh giới chính:

(1) Đáy lớp phủ phân bố sâu nhất tại các điểm đo $\mathrm{PTH}$ và $\mathrm{DPH}$ đạt tới $10-12 \mathrm{~km}$, ở các điểm khác độ sâu khoảng $5 \mathrm{~km}$. Điện trở suất lớp phủ tương

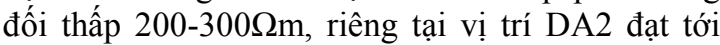
$4.000 \Omega \mathrm{m}$;

(2) Bề mặt Moho - chiều dày vỏ Trái Đất ít biến động, phân bố ở độ sâu trong khoảng 29-32km. Điện trở suất các cấu trúc phân bố giữa đáy lớp phủ và bề mặt này có phân dị cao theo chiều ngang và tăng cao hơn nhiều so với lớp phủ trên (trừ điểm $\mathrm{DA} 2$ ): từ điểm $\mathrm{PTH}$ đến DPH (giữa đứt gãy Sông Hồng và Sông Chảy), dưới điểm LAS (rìa đông bắc) có giá trị trung bình cao $1.200 \Omega \mathrm{m}$, dưới điểm DA2-giá trị trung bình thấp $500 \Omega \mathrm{m}$; các phần còn

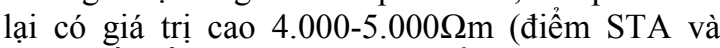
LUS) đến rất cao $10.000 \Omega \mathrm{m}$ (điểm $\mathrm{HN} 3$ và $\mathrm{NDE}$ ); điện trở suất các cấu trúc bên dưới mặt Moho, tức manti trên, ngoại trừ điểm STA và LAS, đều có $x u$ thế giảm so với phần trên bề mặt này, trong đó giảm mạnh nhất ở các điểm PTH tới 15 lần và $\mathrm{DPH}$ là 8 lần, các điểm còn lại - khoảng 2 đến 3 lần.

(3) Bề mặt cấu trúc điện trở suất thấp (độ dẫn điện cao) trong manti ở độ sâu $90 \mathrm{~km}$ phân bố dưới các điểm đo STA, PTH, DPH có giá trị rất thấp 30$50 \Omega \mathrm{m}$ so với $80-140 \Omega \mathrm{m}$ ở bên trên ranh giới này.

Nhìn chung, kết quả đo sâu từ tellua trên tuyến đo này thể hiện sự phân dị tính chất dẫn điện xuyên suốt lớp phủ, trong vỏ Trái Đất và manti của các cấu trúc gắn với đứt gãy Sông Hồng - Sông Chảy (phần chính của ĐGSH), đứt gãy Sông Lô, trong đó cấu trúc Sông Hồng - Sông Chảy còn thể hiện sự phân dị độ dẫn điện ở độ sâu tới $90 \mathrm{~km}$ bên trong manti là thông tin mới hữu ích cho nghiên cứu ĐGSH ở khu vực này.

\section{Một số luận giải về cấu trúc sâu và dị thường địa nhiệt ở ĐGSH theo kết qủa phân tích tài liệu đo sâu từ tellua}

Tính chất dẫn điện của môi trường tự nhiên phụ thuộc chủ yếu bởi các yếu tố chính gồm $[9,16]$ : 
(i) Thành phần khoáng vật; (ii) Trạng thái (độ rỗng, độ ẩm, tính phân lớp,...); (iii) Nhiệt độ. Trong điều kiện tự nhiên, đối với quy mô nghiên cứu vĩ mô chủ yếu lý giải sự biến động tính chất dẫn điện của các cấu trúc khác nhau chỉ có thể dựa vào yếu tố trạng thái (đá nứt nẻ tạo độ rỗng chứa nước làm tăng độ dẫn điện so với đá nguyên khối rắn chắc có độ dẫn điện thấp), với độ sâu nghiên cứu lớn yếu tố nhiệt độ làm tăng độ dẫn điện, ví dụ nước hòa tan muối $\mathrm{NaCl}$ ở nhiệt độ $40^{\circ} \mathrm{C}$ có độ dẫn điện tăng tới hai lần so với điều kiện nhiệt độ bình thường $\left(18^{\circ} \mathrm{C}\right)$, trong khi gradient nhiệt độ bình thường ở vỏ Trái Đất là $25-30^{\circ} \mathrm{C} / 1 \mathrm{~km}$. Dựa trên cơ sở đó có thể đưa ra một số luận giải về đặc điểm cấu trúc sâu và dị thường địa nhiệt cho kết quả phân tích tài liệu đo sâu từ tellua trên tuyến đo cắt qua ĐGSH:

(1) Trên các vị trí có đứt gãy kiến tạo: Đới kẹp giữa đứt gãy Sông Hồng và Sông Chảy, đứt gãy Sông Lô, đứt gãy Phả Lại - Đông Triều (đường 18) là các đới điện trở suất thấp tương đối do vỏ Trái Đất bị dập vỡ và xuất hiện khe nứt tạo điều kiện chứa nước làm cho điện trở suất giảm. Nơi có điện trở suất càng cao phản ánh vỏ Trái Đất càng rắn chắc.

(2) Nơi có chiều dày lớp phủ tăng cao là bề mặt "móng kết tinh" (ký hiệu K trên hình 3) chìm sâu, bề mặt Moho (ký hiệu $\mathrm{M}$ ) nâng lên là chỉ thị quá trình bù đẳng tĩnh nằm trong đới khống chế bởi đứt gãy Sông Hồng và Sông Chảy.

(3) Mức độ giảm điện trở suất của các cấu trúc từ vỏ Trái Đất qua bề mặt Moho vào manti tác động bởi cả hai yếu tố tính chất dập vỡ và tăng nhiệt độ. Ở đới Sông Hồng - Sông Chảy ảnh hưởng của nhiệt độ có ưu thế chính làm cho điện trở suất giảm tới 8 đến 15 lần và còn tiếp tục gia tăng thêm gần ba lần tại mặt ranh giới điện trở suất rất thấp (ký hiệu LR) ở độ sâu 90km, trong khi ở phần vỏ rắn chắc mức độ giảm điện trở suất khi qua mặt Moho không vượt quá ba lần. Phân tích đặc điểm phân bố điện trở suất từ vỏ qua mặt Moho trên toàn bộ mặt cắt cho thấy, tác động nhiệt độ từ manti lên vỏ còn có khả năng được thực hiện bởi quá trình đối lưu nước trong hệ thống khe nứt của đứt gãy cũng là yếu tố chính làm giảm điện trở suất trong vỏ mạnh mẽ nhất ở đới Sông Hồng - Sông Chảy, tiếp đến là đứt gãy Sông Lô, ít hơn cả là đứt gãy Phả Lại - Đông Triều. Dị thường dẫn điện trong manti chính là một nguồn nhiệt sâu tạo ra dị thường dòng nhiệt cao ở đông nam vùng trũng
Sông Hồng, cung cấp nhiệt tạo ra các nguồn nước nóng đã phát hiện được trong vùng (hình 1).

\section{Kết luận}

Đới đứt gãy Sông Hồng ở khu vực châu thổ Sông Hồng bị phủ bởi các trầm tích trẻ nên chỉ có điều kiện nghiên cứu bằng các phương pháp địa vật lý. Ở đây tồn tại dị thường dòng nhiệt cao tương tự như ở nhiều vùng rift và các điểm nước khoáng nóng xuất lộ khá rộng rãi chứng tỏ tính chất hoạt động mạnh mẽ, liên quan đến các hoạt động sâu trong vỏ Trái Đất cần được quan tâm nghiên cứu.

Tiến hành phân tích tài liệu đo sâu từ tellua thực hiện năm 1996 gồm 8 điểm đo trên một tuyến chiều dài $75 \mathrm{~km}$ từ thị trấn Lương Sơn (Hòa Bình) đến thành phố Bắc Ninh, cắt qua các đứt gãy chính của đới ĐGSH cho kết quả là mặt cắt cấu trúc phân bố độ dẫn điện tới độ sâu $100 \mathrm{~km}$, trong đó thể hiện đặc điểm cấu trúc các đới đứt gãy Sông Hồng Sông Chảy, Sông Lô xuyên cắt bề mặt "móng kết tinh", mặt Moho. Đã phát hiện một dị thường dẫn điện phân bố dưới đới đứt gãy Sông Hồng - Sông Chảy, ở độ sâu $90 \mathrm{~km}$, là chỉ thị về khả năng tồn tại nguồn dị thường nhiệt và hiện tượng nâng trồi trong manti.

Trên cơ sở phân tích mối quan hệ giữa tính chất dẫn điện với các yếu tố trạng thái dập vỡ và nhiệt độ đã luận giải dị thường dòng nhiệt và các nguồn nước khoáng nóng liên quan đến nguồn địa nhiệt sâu ở manti phân bố trong đới Sông HồngSông Chảy.

\section{TÀI LIÊU DÃN}

[1] Duchkov A.D., Nguyễn Trọng Yêm, Đinh Văn Toàn, 1992: First estimates of head flow in Vietnam. Sov. Geol. Geophys., 33, 92-96.

[2] Djharikov V.A., Simakin A.G., Epenbaum M.B., 1991: Modeling of possible appearance of granitoid magma during partial melting process of basalt with materials in crust. Press MGU, 2, 3-15 (in Russian).

[3] Harder S., Dinh Van Toan, Nguyen Trong Yem, Trinh Viet Bac, 1996: Preliminary Heat Flow Results from the Hanoi Basin, Vietnam. In monography Terrestrial Heat Flow and Geother. Energy in Asia. Oxford \& IBH Publ. Co. PVT. LTD, 163-172. 
[4] IPIWin-MT v.2.0 user manual. Moscow University, 2002, $15 p$.

[5] Irvine J.N., 1970: Heat transfer during solification of layered intrusions. Canad.J. Earth Sci., vol. 7, No.4, 1031-1061.

[6] Leloup P.H., 1995: The Ailao Shan - Red River shear zone (Yunnan, China), Tertiary transform boundary of Indochina. Tectonophysics 251, 3-84.

[7] Mc Kenzie D., Bikle M.J., 1988: The volume and composition of melt generated by extension of the lithosphere. J. Petrol., 26, 625-679.

[8] Moisenko U.I, Smyslov A.A., 1983: On the earth crust geothermical model of Zabajkalie. Tras. of Lenigrad Society of Naturalists 77 Issue 2, $100-111$.

[9] Nabighian M. (Editor), 1991: Electromagnetic Methods in Applied Geophysics. N.3, v.2, pub.AGU, $520 p$.

[10] Pham Van Ngoc, et al, 1996: Electrical conductivity and structure of the crust around Yen
Bai-Tuyen Quang (Vietnam) from Magnetotelluric Sounding (MTS). C.R.Acad.Sci. Paris, T.323, serie IIa, 651-656.

[11] Spichak V. (Editor), 2006: Electromagnetic sounding of the Earth interior. Elsevier, 380p.

[12] Đoàn Văn Tuyến, Đinh Văn Toàn, Nguyễn Trọng Yêm, Phạm V. N, Boyer D., 1998: Một số kết quả áp dụng phương pháp đo sâu Từ-tellua nghiên cứu cấu trúc sâu đới đứt gãy Sông Hồng. Tc. CKHvTĐ, T.20, 1, 16-20.

[13] Đoàn Văn Tuyến, Đinh Văn Toàn, 2008: Nghiên cứu nguồn địa nhiệt cho phát triển năng lượng sạch ở Việt Nam. Tc. Các Khoa học về Trái Đất, T. 30, 2, 153-160.

[14] Phạm Năng Vũ, 2000: Quá trình biến dạng của đới đứt gãy Sông Hồng trong Kainozoi. Tc Các Khoa học về Trái Đất, T. 22, 4, 278-289.

[15] Zhdanov M., 2002: Geophysical Inverse Theory and regularization problems. Elsevier, $635 p$.

[16] Zhdanov M., 2009: Geophysical Electromagnetic Theory and methods. Elsevier, $848 p$.

\section{SUMMARY \\ Structural features of Electrical conductivity and its relation to anomaly of geothermal heat flow in the Red River Fault zone}

On the Red River plain, anomalies of geothermal heat flows are high enough like as in rift zones, many geothermal hot water sources are distributing largely in the region. It possibly related to the deep activities in the low crust of the Earth. In the 1996, the Institute of Geological Sciences (Vietnam Academy of Science and Technology) under cooperation with the Paris Institute of Physic of the Earth (France) were conducted the survey by magnetotelluric soundings (MTS) for studying deep structures of the Red River Fault zone (RRFZ) in the region.

The paper presents results of data re-interpretation of 8 MTS distributing along the profile about $75 \mathrm{~km}$ in length, started from Luong Son Village (SW site) going through Hanoi City and ended in Bac Ninh town (NE site), perpendicular crossing the main structures of RRFZ. Received results are 2D structural cross-section to $100 \mathrm{~km}$ depth, reflecting features with high electrical conductivity of Red River - Chay River subzone and Lo River fault crossing the "crystallized" surface and Moho discontinuity. One anomaly structure of high electrical conductivity is determined under the Red River - Chay River subzone at the depth $90 \mathrm{~km}$. It is permitting to suggest possibly the presence of one anomaly of high temperature relating to the "intrusion" of mantle here.

By analyzing the features of the high electrical conductivity structures caused by fracture and temperature factors in the crust and mantle, it is allow to explain that, the anomaly of geothermal heat flow and geothermal hot water sources in Red River plain are supported heat from high temperature mantle sources under the Red River - Chay River subzone. 